\title{
Writing (and Reading) as Material Practice: The world of cuneiform culture as an arena for investigation
}

\author{
Roger Matthews \\ University of Reading
}

\begin{abstract}
Let me read the tablets in the presence of the king, my lord, and let me put down on them whatever is agreeable to the king; whatever is not acceptable to the king, I shall remove from them. The tablets I am speaking about are worth preserving until far-off days. ( $7^{\text {th }}$ century BC cuneiform inscription on clay tablet from Nineveh, capital of the NeoAssyrian empire, see Frame and George 2005: 278).
\end{abstract}

In an age where 'the death of the book' is heralded almost daily (Ehrenreich 2011 poetically situates the debates), and where new modes of expression and consumption of the written word are freely elaborated, we are perhaps especially sensitised to the materiality of the writings, and the readings, that inhabit our world. In this chapter, following a brief review of current research, I consider some key questions in the materiality of writing, drawing on case-studies from the world of "cuneiform culture" that dominated the ancient Near East for more than 3000 years from its beginnings around $3200 \mathrm{BC}$ (Radner and Robson 2011).

\section{Current Research into the Materiality of Ancient Near Eastern Texts}

Following a long and occasionally fraught relationship between archaeologists and historians of the ancient Near East (Liverani 1999; Matthews 2003; Zimansky 2005), the topic of textual materiality is increasingly considered in studies by Near Eastern epigraphists and archaeologists working together to achieve shared aims. It has long been appreciated that the shape and format of clay tablets bearing cuneiform script is frequently related to the content of those texts (e.g.

\section{How to cite this book chapter:}

Matthews, R. 2013. Writing (and Reading) as Material Practice: The world of cuneiform culture as an arena for investigation. In: Piquette, K. E. and Whitehouse, R. D. (eds.) Writing as Material Practice: Substance, surface and medium. Pp. 65-74. London: Ubiquity Press. DOI: http:// dx.doi.org/10.5334/bai.d 
Radner 1995) but such associations, and many others, are now being explored in more rigorous detail and with new scientific methods.

In his recent book, Dominique Charpin (2010: 25-42) has articulated a manifesto for what he terms a "diplomatics of Mesopotamian documents", whereby attention of the historian expands beyond the purely textual content of cuneiform documents to a concern with physical form, including materiality (of tablet and stylus), the palaeography of written signs, the layout of texts, and the use of seals on texts (see also van de Mieroop 1999). In the broader context, the historian must also consider issues of how specific texts, or groups of texts, came to be written in the first place and how they came to be preserved within archives, or otherwise, for ultimate discovery in the archaeological record. A model of fruitful collaboration between epigraphy and archaeology is the study by Italian scholars of Ur III texts (late $3^{\text {rd }}$ millennium BC) from southern Iraq currently housed in the British Museum (D’Agostino et al. 2004). Their study combines conventional epigraphy with analytical approaches to a range of material attributes including formal typology of tablet shape and size, location and type of fingerprints, and the varying uses of seals on texts. Most innovative is their application of archaeometric methods (Inductively Coupled Plasma Optical Emission Spectroscopy and Inductively Coupled Plasma - Mass Spectrometry) in order to characterise the clays employed in tablet manufacture. While so far limited in its interpretive scope, their pilot study starts to map out the contours of a future landscape of investigation, offering approaches and methods which may have applicability across and beyond the world of cuneiform culture.

Two larger-scale developments encourage the belief that holistic, integrated approaches to the materiality of texts from the ancient Near East, and beyond, are becoming established in the academic arena, as advocated throughout the 2009 Writing as Material Practice conference (see Piquette and Whitehouse, this volume). Firstly, in April 2010 at the $7^{\text {th }}$ International Congress on the Archaeology of the Ancient Near East (7ICAANE) in London a one-day workshop, organised by Jon Taylor of the British Museum, was devoted to the topic of 'Composition and Manufacture of Clay Tablets'. Papers covered a range of material topics including plant and shell inclusions within clay tablets as potential indicators of provenance and local environment, the recycling of tablets, the possible detection of increasing salinity in the Mesopotamian environment through analysis of diatoms, phytoliths and shells contained within clay tablets, and applications of portable X-Ray Fluorescence (pXRF) to clay tablets. Subsequent publications by Taylor and colleagues confirm the strong trajectory of this area of research (Cartwright and Taylor 2011; Taylor 2011). Secondly, at Heidelberg University a generously-funded Collaborative Research Centre has been established by the German Research Foundation in order to investigate 'Material Text Cultures: Materiality and presence of the scriptural in non-typographic societies', with the commendable ambition to apply a range of scientific and humanities approaches to the study of textual materiality from many societies of the ancient world, including Egypt and Mesopotamia. Here, indeed, a new 'textual anthropology' is taking shape (for information on the new centre see: http://www. materiale-textkulturen.de).

\section{Who Wrote the Text in Question and Why?}

All texts have authors and all texts have reasons for being written and for being read. In considering this question of who wrote the text in question and why, we encounter issues such as the spread and extent of the ability to write and read within specific societies, the role, social status, and training of scribes, and the situation of written texts at the intersection of a range of social components with potentially differing angles of engagement with specific texts. The extent and spread of writing within ancient Near Eastern societies was highly variable through time and space (Figure 1). At its origins in the late $4^{\text {th }}$ millennium вс world of Uruk Mesopotamia, writing 


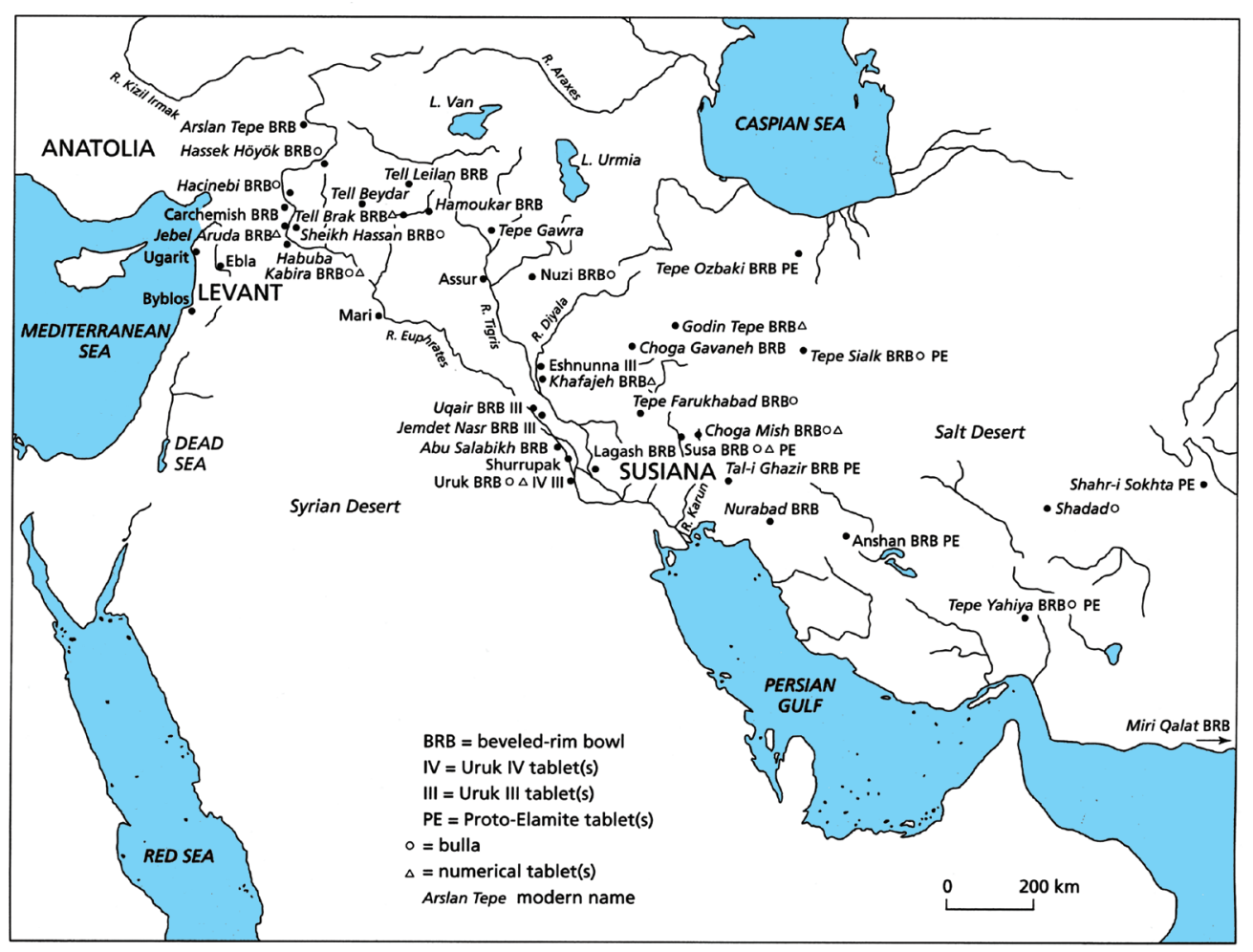

Figure 1: Map of the proto-cuneiform world (after van de Mieroop 2004: 36, map 2.2).

was an instrument of centralised control developed in order to facilitate temple administration of labour and agricultural production (Algaze 2008; Englund 1998; Liverani 2006). The world's earliest writing, in the so-called proto-cuneiform tradition, was produced exclusively by and for bureaucrats working on behalf of large centralised institutions at the very origins of the state. Echoes of this role for writing are attested in outposts of Uruk control along major trade routes reaching out from Mesopotamia, as for example at Godin Tepe in central-west Iran where a small collection of clay tablets, some with seal impressions, indicate the presence of a cadre of Uruk, or Uruk-influenced, bureaucrats exercising their newly developed administrative technology in order to control local agricultural activity and production (Matthews 2013). The quantities and range of commodities attested in the Godin Tepe texts, such as small quantities of domestic animals and dairy produce, are so limited that one wonders whether their administration through written texts was not so much a bureaucratic necessity as a means of demonstrating the power of those who could write over those who could not. As Algaze points out (2008: 138), from its earliest manifestation the written text appears to align with Lévi-Strauss' dictum that "the primary function of writing, as a means of communication, is to facilitate the enslavement of other human beings" (1964: 292).

In later times cuneiform culture expanded to incorporate a broader remit of social and economic engagement (Figure 2). Writing, increasingly regularised in its execution and with a muchreduced sign repertoire, was used both in a wider array of roles - for letters, contracts, lists, treaties, prayers and annals - and also to express a diverse wealth of largely unrelated languages, including Sumerian, Akkadian (Assyrian and Babylonian), Hurrian, Hittite, Elamite, Ugaritic, and others distributed across the ancient Near East (Zimansky 2005). The extent of the ability to write and read needs investigation in each individual case through time and space. Charpin (2010: 


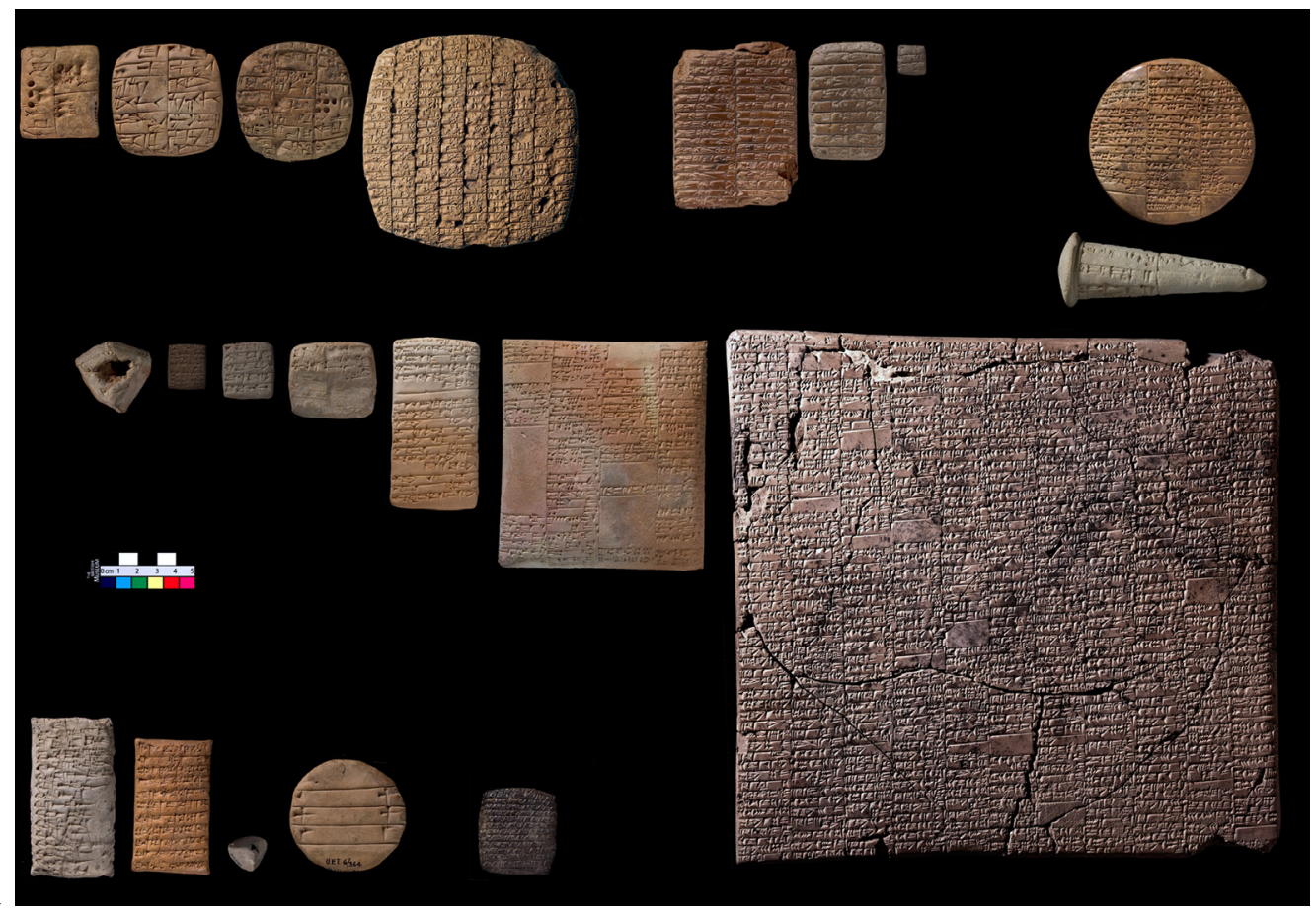

a
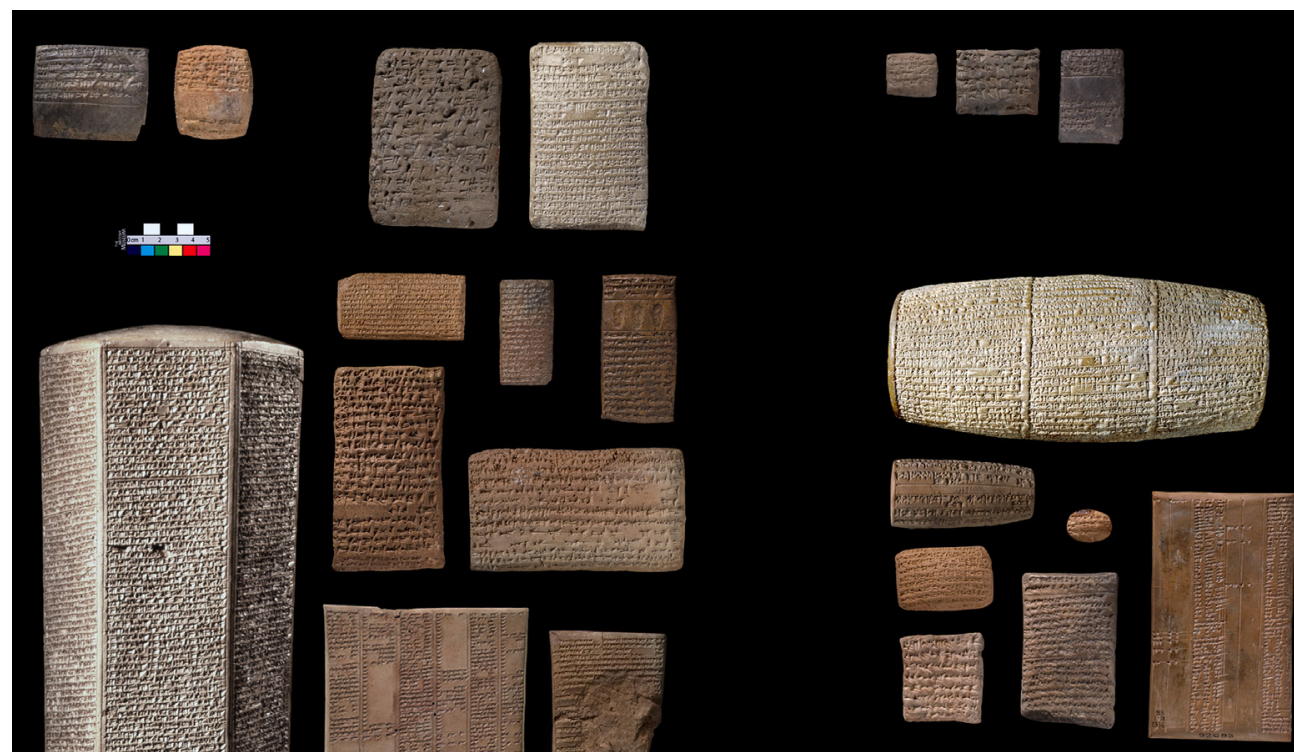

b
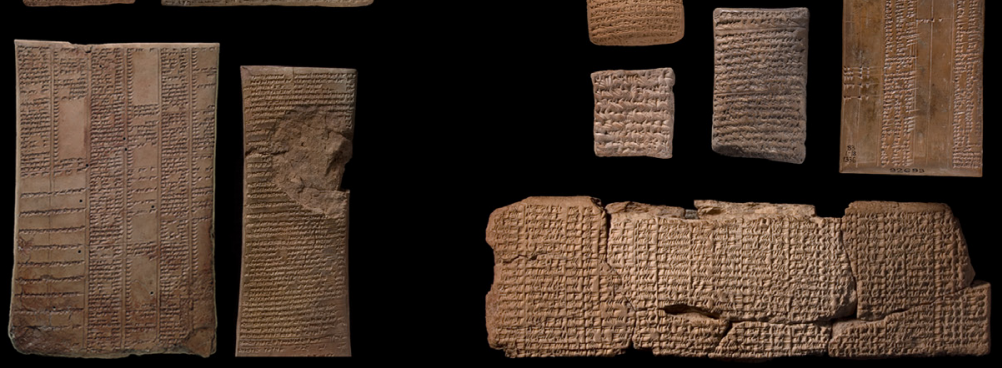
Figure 2: A sample of the variety of shapes and sizes of cuneiform texts on clay (after Taylor 2011: 9-10, figs 2A and 2). a) (Top) Archaic: administrative (BM 128826); Early Dynastic: administrative (BM 15829, BM 29996, BM 102081); Old Akkadian: administrative (BM 86281, BM 86289, BM 86332); Ur III: administrative (BM 24964), cone (BM 19528). (Middle) Ur III: administrative (BM 19525, BM 104650, BM 13059, BM 19176, BM 26972, BM 26950, BM 110116). (Bottom) Old Babylonian: administrative (BM 16825), letter (BM 23145), administrative (BM 87373), scholarly (UET 6/3 64, on loan to the British Museum; Old Assyrian: administrative (BM 120548). (C) Trustees of the British Museum; b) (Top) Nuzi: administrative (BM 17616, BM 26280); Amarna letters (British Museum, ME 29883, ME 29785); Middle Babylonian: administrative (BM 17689, BM 17673, BM 17626). (Left) Neo-Assyrian prism (BM 91032), scholarly (British Museum, K 750), letter (British Museum, K 469), administrative (British Museum, K309a), scholarly (British Museum, K 159, K 195, K 4375, K 2811). (Right) Neo-Late Babylonian: barrel (BM 91142, BM 30690), administrative (BM 29589), scholarly (BM 92693), administrative (BM 30912, BM 30690), scholarly (BM 38104, BM 34580). (C) Trustees of the British Museum.

7-24) has questioned the conventional assumption that reading and writing in Mesopotamia were solely "the business of specialists", arguing that differing levels of competence in writing, and reading, the cuneiform script are attested by texts from a range of archaeological contexts. In the early $2^{\text {nd }}$ millennium $\mathrm{BC}$ there is good evidence that Assyrian merchants were capable of writing and reading by themselves, without input from specialist scribes, employing a limited syllabary of fewer than 70 signs (Charpin 2010: 19). Lion (2011) has stressed that in the same period in Assyria and Babylonia significant numbers of women as well as men could read and write.

Veldhuis (2011) has explored the versatility inherent in the cuneiform writing system, which enabled several types and degrees of literacy to co-exist. Not everyone had to be a top-level scholar, with years of expert training behind them, in order to participate in the cuneiform system. Veldhuis identifies three broad categories of cuneiform literacy - functional, technical, and scholarly. Functional literacy could be attained by a wide range of citizens of the Mesopotamian city-states, in particular during the huge expansion of the uses of writing during the early $2^{\text {nd }}$ millennium $\mathrm{BC}$, the Old Babylonian period, while technical literacy relates to expertise in specialist areas of cuneiform practice, such as divination and mathematical texts. The most accomplished scribes can be described as 'scholarly literate', defined by Veldhuis as exhibiting "the pride of the scribes in their craft, emphasizing and even increasing complexity and demonstrating the joy of discovering rare and unusual features of the system" (Veldhuis 2011: 74). It would make an interesting exercise to track the shifting proportions of these three types of literacy through the 3000 -year history of the cuneiform world and to consider their variability in the light of changing political and social regimes.

A related issue concerns societies which choose not to write. In a rare study of this question Lamberg-Karlovsky (2003) surveys through time the interaction of literate societies with nonliterate societies across the ancient Near East, detecting only one example (the short-lived ProtoElamite phenomenon) of a non-literate society adopting the practice of writing through contact with a literate society. His interpretation is that indigenous societies deliberately rejected writing because of its association with forms of externally-imposed control and with specific religious and social contexts that were alien, indeed hostile and exploitative, to non-literate societies.

How were textual traditions maintained and sustained through time and space? The transmission and control of written knowledge in the ancient Near East was materialised through two intersecting networks, forming a chrono-spatial framework. A horizontal network in space involved largely elite and merchant elements of states and empires, operating across the geographic span of specific states by means of movement of letters, contracts, and archives as well as of the writing 
skills and capabilities, in the form of scribes, (the website Knowledge and Power in the NeoAssyrian Empire provides excellent coverage of these and related issues: http://oracc.museum. upenn.edu/saao/knpp/). But there was also a network of vertical transmission, and indeed control, of knowledge through time which was sustained and enriched by the very materiality of cuneiform culture, through not just decades or centuries but over millennia.

Archives of clay tablets appear from the very start of the cuneiform tradition and last until its end (Pedersén 1998). They served as a major means of the vertical transmission of knowledge through the curation of archives and libraries within the context of palaces and temples in imperial core cities, as attested at Nineveh and many other cities. Assurbanipal's $7^{\text {th }}$-century BC library of $c .28,000$ clay tablets (plus an unknown number of wooden texts that have not survived) constitutes vivid evidence that the king could take a personal and learned interest in the reception, definition, and transmission of knowledge through time (Frame and George 2005). At a deeper level, we can also see a role for the materiality of texts in the persistence of templates of social power, of cultic belief and practice, of knowledge control and transmission through the entire epoch of cuneiform culture.

Why do people stop writing texts? While much study has been invested in the origins of scripts and writing traditions, less attention has been devoted to what has been called "script obsolescence" (Houston et al. 2003; for numerous case-studies of the rise and demise of languages and their texts see also Baines et al. 2008; Ostler 2005). The only answer can be that people stop writing, at all or in specific ways, when the social context of their writing disappears or is transformed beyond sustainability. An illustrative example is the steady disappearance of skills in Arabic calligraphy in contemporary Lebanon, and elsewhere in the Islamic world, due to the rise of computergenerated calligraphy. Here a technological shift, embedded in social change, is transforming classical calligraphy into "a visual art rather than a useful tool" (http://www.alarabiya.net/articles/2011/07/30/160088.html).

\section{Who Was Meant to See or Read the Text?}

With the question of who was meant to see or read a given text, we are concerned with issues such as audience and accessibility of texts. The earliest proto-cuneiform texts were not designed to be read outside the administrative sphere, and so to the historian today they can be laconic and obtuse in their content. Even their language (or languages?) is unreachable through the distribution of incised signs, some 900 of them, that early scribes marked on the soft clay tablets with their styli. Their most approachable component is the array of numerical systems employed to count and account for quantities of people, animals, and products as they made their way through the bureaucratic world (Chrisomalis 2010 provides a brilliant comparative study of the world's systems of numerical notation, including those of ancient Mesopotamia).

How were cuneiform texts read? Charpin (2010: 20-22) proposes that in almost every case a cuneiform text would be read aloud either by a literate reader to him / herself or by a scribe to a non-literate listener, such as an official or royal recipient. Additionally, Charpin cites rare evidence that scribes might silently read texts to themselves as a means of rapidly checking their content. When we sit today in the British Museum study room and see the distinguished cuneiform scholars silently working their way through trays of broken clay tablets, perhaps we should encourage them occasionally to voice their readings aloud so that we might share in the aurality of the text and thereby gain an idea of how an ancient reader / listener might have encountered the written word (for a bold attempt at spoken Akkadian, by Irving Finkel of the British Museum, see http:// www.bbc.co.uk/news/world-middle-east-13733615). 


\section{What Was the Physical Medium and Context of the Text?}

The analysis of clays used to make tablets in the cuneiform tradition is in the early stages of development (Taylor 2011). Most significant has been the work of Yuval Goren and colleagues in applying mineralogical and chemical analyses to corpora of clay tablets in order to explore issues of provenance and movement of inscribed clay tablets (Goren et al. 2004). The basic premise of their work is that "Even within an assemblage of documents composed by the same individual, each tablet should be treated as a unique artefact, created under very special and distinctive circumstances" (Goren et al. 2004: 316). As mentioned above, methods have built upon earlier uses of Neutron Activation Analysis, applying Inductively Coupled Plasma analyses combined with systematic study of micropalaeontology and micropalaeobotany in order to characterise inclusions within clay matrices (Cartwright and Taylor 2011). In a pioneering and exhaustive study by Goren et al. of around 300 clay tablets found at el-Amarna in Egypt, dated to the mid-14 $4^{\text {th }}$ century BC, these approaches have been integrated with geological and historical studies in the generation of truly significant interpretations relating to the selection of clays for tablet manufacture, the deliberate addition of inclusions to the clay, the processes of firing of tablets to ensure durability, and a host of insights into the historical specifics of cuneiform communication between city-states of several regions of the ancient Near East in the international age of the Late Bronze Age.

The most promising recent development has been the application of a new generation of portable X-Ray Fluorescence (pXRF) analysers to clay tablets from the Near Eastern past, as conducted by Goren et al. (2011) on tablets from the Hittite capital Hattusa and other sites. Increasingly sensitive capabilities of pXRF, coupled with the ability to characterise clay elements through noninvasive, non-destructive means, have opened a new chapter in archaeometric investigation of clay tablets and clay sealings. As touched on previously, the full implications of the new technology have yet to be articulated and realised but there is hope that access can increasingly be had to multiple museum collections of tablets and sealings in systematic programmes of analysis and interpretation. Such programmes will need to comprise integrated strategies involving archaeologists, historians, geologists and materials scientists.

The materiality of each text has a specific and contingent trajectory. The display of Neo-Assyrian texts, cut into stone slabs, within their palatial contexts has been an especially fruitful arena for integrated epigraphical and archaeological investigation, centring on the physicality of text. To the forefront has been the work of John Russell (1999) whose meticulous study of the location of stone inscriptions within Neo-Assyrian palaces begins with a vivid description of the materiality of text in Assurnasirpal II's $9^{\text {th }}$ century BC palace at Nimrud:

"Once upon a time, a long time ago, anyone fortunate - or unfortunate - enough to enter the palace of 'the king of the world, king of Assyria', would have been surrounded by texts. In the first great Neo-Assyrian palace, the palace of Assurnasirpal II at Kalhu (Nimrud), texts were everywhere. The bull and lion colossi in the major doorways carried texts. The pavement slabs in those doorways, and in every other doorway, carried texts. Every floor slab in every paved room carried a text. And each one of the hundreds of wall slabs, sculptured and plain, carried a text" (Russell 1999: 1).

Russell (1999) interprets the role of texts within the architectural scheme of Neo-Assyrian palaces at several levels, including the materialisation of a desire to mark royal ownership of the newly-built palace, the decorative transformation of "dull structural fittings into active royal monuments", the affirmation of a royal aura to the palatial monument, and above all the agency of texts as "visual icons of kingship" (Russell 1999: 230). 


\section{How Representative are Surviving Texts of the Corpus of Their Place and Period?}

Scholars of the ancient Near East are fortunate in that the subjects of our study wrote on clay. We already have hundreds of thousands of cuneiform-script clay tablets in our museums, and there are certainly many times that number still to be excavated - hopefully only through modern legal archaeological investigation. The recent looting and destruction of entire ancient cities in southern Iraq (Stone and Farchakh Bajjaly 2008) has without doubt led to serious disruption to the evidential base of cuneiform culture, in particular as regards its all-important archaeological context, but we have no way of measuring the full extent of that disruption. Nevertheless, it is important that we consider how representative is our so-far recovered collection of cuneiform texts. A thoughtful comment on this topic is provided by Aage Westenholz (2002):

"I reckon that of all the texts that were produced, 99 per cent were destroyed, most of it quite soon - the clay of the tablets was recycled. Of the 1 per cent that survived and is still buried in the ground, about 1 per cent has been recovered in excavations; and of that, about one-half has been made available to scholarship in often less-than-adequate publications. A sample of one in 20,000, quite unevenly distributed by random chance!" (Westenholz 2002: 23-24).

It is worth noting that ancient Near Eastern scribes also wrote on materials other than clay tablets and stone monuments, especially towards the end of the cuneiform period. Writing-boards, papyri and parchments are attested by occasional archaeological evidence, such as waxed boards from Nimrud (Wiseman 1955) and the Ulu Burun ship-wreck (Payton 1991; see also Whittaker, this volume), and by depictions on Assyrian reliefs. The Great Temple at Hattusa, capital of the Hittite empire of Anatolia, employed in the $13^{\text {th }}$ century вс no fewer than 52 scribes, 33 of whom were noted as writing on wooden boards not on clay tablets (Bryce 2002: 60). This scribal proportion suggests that as much as $60 \%$ of the Hittite written record may have been recorded on wood. Needless to say, none of those wooden tablets have yet been found in the archaeological record while so far more than 30,000 clay tablet fragments have been recovered from Hattusa and other Hittite sites (Collins 2007: 141). There are also rare instances of cuneiform script cut into metal plaques such as the famous bronze treaty of Tudhaliya IV from the Sphinx Gate at Hattusa (Otten 1988).

We can make a final point about the durability and materiality of cuneiform culture. The transmission of knowledge from the ancient Near East to scholars today is largely direct and physical, without intermediaries, unlike most extended texts from the Classical world which reach us in the form of the modern printed page (or digital screen) having been copied and often altered over centuries of transmission through a variety of media. Today we can hold in our hands the very first exemplars of writing from the city of Uruk, impressed on the soft clay some 5200 years ago. We can feel the weight and shape of the tablet, even smell its clay, very much as the ancient scribe did. Our encounter with cuneiform culture through the shape and texture of its surviving clay tablets keeps us firmly attached to its ancient materiality, preserved indeed from far-off days.

I conclude by briefly considering some issues of broader relevance relating to the materiality of writing. One main area of study addressed in several papers at the conference (see Piquette and Whitehouse, this volume) relates to the sources of raw materials and the processes of manufacture of the supports used for writing (primarily clay tablets in the case of cuneiform writing); these studies are relevant to assessing who the writers and readers might have been, as well as who else might have been involved in the creation and consumption of the finished artefacts. The combination of traditional epigraphic studies (concerned with the content of texts) with the study of 
both the materiality of the inscribed artefacts and their archaeological contexts offers the greatest interpretative possibilities.

The relationship of materiality to the contexts of storage and display is also important: in the cuneiform world there is a strong contrast between the clay tablets, the majority of which come from archive contexts and were probably intended for use by those who could read them, and inscriptions on stone which were mostly situated in public or semi-public places and were meant to be seen and to impress a wide range of people including those, probably the majority, who could not actually read them, as in the Neo-Assyrian palaces described above. The materiality of writing on stone set up in public places is clearly related to the exercise and display of power by elites.

Another important aspect of the materiality of writing supports, as well as that created through the application of materials to surfaces, relates to their likelihood of preservation and survival both in ancient times and down to the present day. Taking of account of what types of writing or related cultural context may not be represented archaeologically is equally important for understanding the various roles it played in past lives. The development of holistic, integrated approaches to the materiality of cuneiform texts is well underway, as I aim to have illustrated here. The application and continued development of methods which integrate material perspectives alongside general archaeological and philological methods are vital for fuller understandings of written culture.

\section{References}

Algaze, G. 2008. Ancient Mesopotamia at the Dawn of Civilization. Chicago: University of Chicago Press. DOI: http://dx.doi.org/10.7208/chicago/9780226013787.001.0001

Baines, J., Bennet, J. and Houston, S. D. 2008. The Disappearance of Writing Systems: Perspectives on literacy and communication. London: Equinox.

Bryce, T. 2002. Life and Society in the Hittite World. Oxford: Oxford University Press.

Cartwright, C. and Taylor J. 2011. Investigating Technological and Environmental Evidence from Plant Remains and Molluscs in Cuneiform Tablets. British Museum Technical Research Bulletin 5: $67-72$

Charpin, D. 2010. Writing, Law, and Kingship in Old Babylonian Mesopotamia. Chicago: University of Chicago Press. DOI: http://dx.doi.org/10.7208/chicago/9780226101590.001.0001

Chrisomalis, S. 2010. Numerical Notation: A comparative history. Cambridge: Cambridge University Press. DOI: http://dx.doi.org/10.1017/CBO9780511676062

Collins, B. J. 2007. The Hittites and Their World. Atlanta: Society of Biblical Literature.

D’Agostino, F., Pomponio, F. and Laurito, R. 2004. Neo-Sumerian Texts from Ur in the British Museum. Messina: Grafica Cristal.

Ehrenreich, B. 2011. The Death of the Book. Los Angeles Review of Books. 18 April. http://lareviewofbooks.org/essay/the-death-of-the-book [accessed 7 November 2013]

Englund, R. K. 1998. Texts from the Late Uruk Period. In Bauer, J., Englund, R. K. and Krebernik, M. (eds), Mesopotamien: Späturuk-Zeit und Frühdynastische Zeit (Orbis Biblicus et Orientalis 160/1). Freiburg: University of Freiburg, 13-233.

Frame, G. and George, A. R. 2005. The Royal Libraries of Nineveh: New evidence for king Ashurbanipal's tablet collecting. Iraq 67: 265-284.

Goren, Y., Finkelstein, I. and Na'aman, N. 2004. Inscribed in Clay: Provenance study of the Amarna Letters and other ancient Near Eastern texts. Tel Aviv: Tel Aviv University.

Goren, Y., Mommsen, H. and Klinger, J. 2011. Non-Destructive Provenance Study of Cuneiform Tablets Using Portable X-Ray Fluorescence (pXRF). Journal of Archaeological Science 38(3): 684-696. DOI: http://dx.doi.org/10.1016/j.jas.2010.10.020 
Houston, S., Baines, J. and Cooper, J. 2003. Last Writing: Script obsolescence in Egypt, Mesopotamia, and Mesoamerica. Comparative Studies in Society and History 45: 430-479. DOI: http:// dx.doi.org/10.1017/S0010417503000227

Lamberg-Karlovsky, C. C. 2003. To Write or Not to Write. In Potts, T., Roaf, M. and Stein, D. (eds), Culture through Objects: Ancient Near Eastern studies in honour of P. R. S. Moorey. Oxford: Griffith Institute, 59-75.

Lévi-Strauss, C. 1964. Tristes Tropiques. New York: Atheneum.

Lion, B. 2011. Literacy and Gender. In Radner, K. and Robson, E. (eds), The Oxford Handbook of Cuneiform Culture. Oxford: Oxford University Press, 90-112. DOI: http://dx.doi.org/10.1093/ oxfordhb/9780199557301.013.0005

Liverani, M. 1999. History and Archaeology in the Ancient Near East: 150 years of a difficult relationship. In Kühne, H., Bernbeck, R. and Bartl, K. (eds), Fluchtpunkt Uruk: Archäologische Einheit aus Methodischer Viefalt. Schriften für Hans Jörg Nissen. Rahden: Verlag Marie Leidorf, 1-11.

Liverani, M. 2006. Uruk: The First City. London: Equinox.

Matthews, R. 2003. The Archaeology of Mesopotamia: Theories and approaches. London: Routledge.

Matthews, R. 2013. The Power of Writing: Administrative activity at Godin Tepe, central Zagros, in the later $4^{\text {th }}$ millennium BC. In Petrie, C. A. (ed.), Ancient Iran and Its Neighbours. Oxford: Oxbow Books, 327-341.

Ostler, N. 2005. Empires of the Word: A language history of the world. London: Harper Collins.

Otten, H. 1988. Die Bronzetafel aus Boğazköy: ein Staatsvertrag Tuthalijas IV. Wiesbaden: Harrassowitz.

Payton, R. 1991. The Ulu Burun Writing-Board Set. Anatolian Studies 41: 99-106. DOI: http:// dx.doi.org/10.2307/3642932

Pedersén, O. 1998. Archives and Libraries in the Ancient Near East, 1500-300 BC. Bethesda: CDL Press.

Radner, K. 1995. The Relation Between Format and Content of Neo-Assyrian Texts. In Mattila, R. (ed.), Nineveh 612 BC: The glory and fall of the Assyrian Empire. Helsinki: University of Helsinki Press, 63-77.

Radner, K. and Robson, E. (eds) 2011. The Oxford Handbook of Cuneiform Culture. Oxford: Oxford University Press. DOI: http://dx.doi.org/10.1093/oxfordhb/9780199557301.001.0001

Russell, J. 1999. The Writing on the Wall: Studies in the architectural context of Late Assyrian palace inscriptions. Winona Lake: Eisenbrauns.

Stone, P. G. and Farchakh Bajjaly, J. 2008. The Destruction of Cultural Heritage in Iraq. Woodbridge: Boydell and Brewer.

Taylor, J. 2011. Tablets as Artefacts, Scribes as Artisans. In Radner, K. and Robson, E. (eds), The Oxford Handbook of Cuneiform Culture. Oxford: Oxford University Press, 5-31. DOI: http:// dx.doi.org/10.1093/oxfordhb/9780199557301.013.0001

van de Mieroop, M. 1999. Cuneiform Texts and the Writing of History. London: Routledge.

van de Mieroop, M. 2004. A History of the Ancient Near East ca. 3000-323 BC . Oxford: Blackwell Publishing.

Veldhuis, N. 2011. Levels of Literacy. In Radner, K. and Robson, E. (eds), The Oxford Handbook of Cuneiform Culture. Oxford: Oxford University Press, 68-89. DOI: http://dx.doi.org/10.1093/ oxfordhb/9780199557301.013.0004

Westenholz, A. 2002. The Sumerian City-State. In Hansen, M. H. (ed.), A Comparative Study of Six City-State Cultures. Copenhagen: C. A. Reitzels, 23-42.

Wiseman, D. J. 1955. Assyrian Writing-Boards. Iraq 17: 3-13.

Zimansky, P. 2005. Archaeology and Texts in the Ancient Near East. In Pollock, S. and Bernbeck, R. (eds), Archaeologies of the Middle East: Critical perspectives. Oxford: Blackwell, 308-326. 